\title{
VISUAL BRANDING PRODUK BELIMBING OLAHAN UMKM DEPOK MELALUI DESAIN LOGO
}

\author{
Ariefika Listya ${ }^{1}$, Yayah Rukiah ${ }^{2}$ \\ Universitas Indraprasta PGRI Jakarta Selatan \\ JI. Nangka No. 58 C (TB. Simatupang), Tanjung Barat, Jagakarsa, RT.5/RW.5, Jakarta Selatan 12530 \\ ariefikalistya@gmail.com
}

Diterima: 3 Juli 2018

Direvisi Akhir: 25 Juli 2018

Disetujui terbit: 12 Agustus 2018

\begin{abstract}
Abstrak: Penelitian ini berfokus pada desain logo sebagai visual branding produk lokal asal Depok produksi Usaha Mikro, Kecil dan Menengah (UMKM). Depok memiliki komoditas pertanian unggulan yakni belimbing. Ada lima brand produk belimbing olahan di Depok, yaitu Rasa Dewa, Totoka, Delira, Maharani, dan Olavera. Penelitian ini menggunakan metode kualitatif dengan pendekatan estetika dan pendekatan ilmu pemasaran. Data dikumpulkan melalui observasi, wawancara dan studi literatur. Observasi dilakukan dengan mengamati keberadaan logo pada kemasan dan media promosi. Fungsi utama logo adalah untuk membentuk identitas dan membedakannya dengan pesaing, namun desain logo dari kelima brand tersebut memiliki kemiripan dan nampaknya belum kuat identitasnya. Selain itu beberapa diantaranya kurang konsisten dalam implementasinya ke media kemasan maupun media promosi, padahal identitas yang kuat dan branding yang baik diperlukan UMKM agar berdaya saing. Penelitian ini bertujuan mengetahui desain logo sebagai visual branding kelima brand UMKM Depok terkait identitas brand sebagai produk lokal asal Depok. Hasil penelitian menunjukkan beberapa brand tersebut belum memiliki keunikan tersendiri dan identitas yang kuat melalui logonya, dan belum merepresentasikan produk lokal asal Depok melalui logonya.
\end{abstract}

Kata kunci: logo, visual branding, UMKM, Depok

\begin{abstract}
This research focuses on logo design as visual branding of local product produced by SMEs in Depok. Depok has a special plantation product, namely starfruit. There are five brands which produce the product: Rasa Dewa, Delira, Totoka, Maharani and Olavera. This qualitative research uses iconography as aesthetic approach and marketing science approach. Data is collected by observation, interview, and literature study. The elements of logo on the packaging and also promotion media was observed. The main function of a logo is to shape the identity and differentiate it from competitors, but the logo design of those five brands has similarities and their identities do not seem strong yet. In addition, some of them have a less consistency in its implementation to the packaging and promotion media, whereas a strong identity and strong branding are required by SMEs to build competitiveness. This study aims to figure out the logo design as visual branding of five brands of UMKM Depok related to brand identity as a local product of Depok. The result of the research shows that some brands do not have their own uniqueness and strong identity through their logo and have not represented the local product from Depok through their logos.
\end{abstract}

Keywords: logo, visual branding, SMEs, depok

Penulis adalah para dosen DKV pada Program Studi Desain Komunikasi Visual Universitas Indraprasta PGRI. Penulis Pertama menfokuskan pengajaran, penelitian dan pengabdian masyarakatnya pada bidang visual branding bagi UMKM termasuk memberikan pelatihan bagi UMKM. Selain itu juga menjadi konsultan desain dan Strategic Planner pada firma desain Etvoilans Indonesia. Penulis kedua memfokuskan pada bidang komputer grafis dan dunia grafika. 


\section{PENDAHULUAN}

Desain idealnya menyejahterakan manusia. Berbagai penelitian desain baik dalam hal rancangan, proses, dan hasil dilakukan guna menghasilkan desain yang lebih baik. Salah satu penelitian desain terhadap hasil ialah kajian atas beredarnya karya desain. Logo merupakan karya desain yang melibatkan unsur desain (bentuk, warna, tekstur, ruang) yang berfungsi sebagai identitas suatu entitas untuk membedakannya dengan yang lainnya. Logo dalam fungsinya sebagai identitas visual utama dalam branding, dituntut agar merepresentasikan suatu entitas secara visual baik secara langsung atau abstrak.

Secara estetis, logo harus berbeda dan menjadi ciri khas dari suatu brand. Fenomena menarik yang nampaknya kurang sejalan dengan peran desain logo dalam branding terdapat pada brand UMKM Depok. Produk dalam kategori yang sama yakni makanan dan minuman belimbing olahan teridentifikasi ada lima brand yakni Rasa Dewa, Totoka, Maharani, Delira dan Olavera yang desain kemasannya nampak mirip termasuk logonya. Adapula brand yang logonya lebih dari satu jenis karena produknya bervariasi, hal ini bertentangan dengan apa yang dinyatakan oleh Van den Bosch, de Jong dan Elving (2006: 140) dimana terlalu banyak variasi visual dapat mengakibatkan ketidakfokusan impresi.

Saat ini masih banyak UMKM yang belum membangun branding produknya dengan baik sejalan oleh pernyataan Sudarwati dan Satya (2013:100) bahwa pengembangan brand UMKM harus dilakukan oleh pelaku UMKM jika ingin tetap bertahan dalam persaingan global. Kendala yang muncul dalam pengembangan brand terutama terjadi dikarenakan adanya kesalahpahaman pelaku UMKM dalam memahami brand. Eka Sofyan sebagai pemilik Paprieka Studio, yang berfokus pada brand visual identity menyatakan brand harus mempunyai identitas yang kuat, yang membedakannya dengan pesaing, identitas tersebut harus terkomunikasikan secara visual.

Fenomena kemiripan identitas visual dan kurangnya konsistensi visual dalam visual branding ini menjadi ketertarikan peneliti untuk dikaji lebih lanjut 
mengenai bagaimana visual branding produk belimbing olahan UMKM Depok melalui desain logonya terkait aspek formalistik dan konsistensinya?

\section{KAJIAN TEORI}

Berkaitan dengan visual branding, dirasa perlu untuk mencari definisidefinisi dasarnya. Brand menurut Kotler (2000: 443) adalah sebuah nama, kata, tanda, simbol, atau desain, atau kombinasinya yang mengidentifikasi barang atau jasa dari penjual maupun kelompok penjual dan untuk membedakannya dari pesaing. Branding, terbentuk dari kata dasar brand ditambah imbuhan -ing berarti proses sesuai dengan definisi Wheeler (2011: 6) Branding adalah sebuah proses membangun kesadaran brand dan mengembangkan loyalitas pelanggan. Membangun brand produk dicirikan oleh nilai tambah pada manfaat fungsional inti dari produk tersebut untuk membentuk keunikan dari pesaing, termasuk citra brand, posisi brand dan identitas brand (Ahonen, 2008). Oleh Karena itu, dalam membangun brand, diperlukan identitas visual.

Elemen identitas visual brand yang utama salah satunya adalah logo dengan fungsi dasar identifikasi dan diferensiasi. Logo secara langsung akan mengidentifikasi dengan brand, itulah kekuatan logo (Hardy, 2011: 3). Ada beberapa tipe logo yang dibuat dari nama entitas, ditampilkan dalam bentuk unik, dari figuratif sampai dengan yang abstrak, yang kemungkinan tidak ada hubungannya secara langsung dengan nama entitasnya maupun aktivitasnya (Farhana, 2012). Elemen brand yang penting dipertimbangkan salah satunya warna. Pengenalan terhadap warna justru terjadi lebih dahulu dibanding bentuk. Warna adalah salah satu cara terbaik dalam mengusahakan brand menjadi mudah diingat serta unik (Wheeler, 2011: 128). Brand yang mempunyai warna khas dapat membantu meluaskan ke banyak media dari kemasan sampai sosial media (Wheeler, 2011: 130).

Selain logo dan warna, tipografi juga mempunyai peranan penting dalam branding. Bentuk, format dan pengaturannya perlu dipertimbangkan (Wheeler, 
2011). Jika jenis huruf telah digunakan dalam sebuah logo, maka huruf tersebut akan sering dikombinasikan dengan gambar. Saat memadukannya dengan gambar atau ilustrasi, sebaiknya saling melengkapi atau berlawanan namun harus selalu berhierarki visual dan terlihat seimbang secara keseluruhan (Krause dalam Kirk, 2013: 6).

Elemen Identitas visual suatu brand erat kaitannya dengan estetika. Estetika tidak terlepas dari budaya, ekonomi, dan komoditas, dimana visual branding merupakan titik penting dalam hubungan bidang-bidang tersebut (Bennett et al, 2008; Bourdieu, 1984; Power, 2004 dalam Davidson, 2009: 884). Pendekatan estetika merupakan pendekatan khusus yang menekankan aspekaspek seni dan desain dalam kaitannya dengan daya tarik estetik (Walker, 2010). Aspek formalistik (bentuk dan warna) dari sebuah desain berfungsi secara estetis dan fungsional serta memiliki makna tertentu. Identitas visual memerlukan konsistensi pada implementasi di berbagai media. Terlalu banyak variasi visual dapat mengakibatkan ketidakfokusan impresi (Van den Bosch, de Jong \& Elving, 2006: 140).

Penelitian mengenai branding entitas (produk, tempat wisata, dan lainnya) yang berhubungan dengan daerah tertentu biasanya mengangkat identitas daerah dan kelokalannya. Salah satu penelitian mengenai identitas brand pada produk minuman anggur di Eropa memperoleh temuan bahwa merek regional (regional brand) di Perancis tidak mengubah identitas kelokalannya supaya konsumen mengasosiasikannya sebagai produk khas daerah itu (Durrieu, 2008: 13). Penelitian di Indonesia mengenai identitas visual brand dilakukan oleh Haiqal dan Hidayat (2017: 189) yang mengkaji identitas visual 3 tempat wisata sejenis dalam penelitiannya mengenai rancangan Identitas visual bagi wisata kerajinan Raja Polah dimana ketiganya menggambarkan konsep visual dan tema dari tiap daerah pariwisata. Setiap logo mempunyai ciri khas yang berbeda satu sama lain yang menggambarkan identitas daerahnya. Penelitian lainnya oleh Septiningtyas dan Soewardikoen (2018) menghasilkan rancangan logo bagi Sasirangan Banjarbaru 
berupa logogram yang mengambil unsur etnik khas bordir serta logotype dari satu jenis huruf yang salah satu hurufnya dikreasikan sehingga menjadi unik dan berciri khas.

Berdasarkan hal tersebut, maka aspek formalistik desain logo yang terdiri atas bentuk figuratif objek, bentuk abstrak, bentuk huruf, dan warna adalah aspek penting yang akan dikaji. Kriteria identitas visual termasuk desain logo yang baik bagi entitas yang berhubungan dengan suatu daerah berdasarkan kajian teori diatas diantaranya pertama, aspek formal suatu desain logo sebagai bagian dari visual branding idealnya berbeda dengan bentuk formal desain logo pesaingnya; kedua, aspek formal logo dapat menggambarkan identitas daerahnya sebagai kekhasan; ketiga, aspek formal secara estetis memiliki makna tertentu yang idealnya berkaitan dengan brand-nya; kemudian terakhir, desain logo seharusnya juga terimplementasikan secara konsisten pada semua media agar menciptakan impresi.

\section{METODE PENELITIAN}

Penelitian kualitatif ini dilakukan di Depok, Jawa barat. Selain pendekatan estetika, masalah yang menjadi fokus penelitian juga didekati dari sisi ilmu pemasaran dimana branding adalah bagian dari kajian ilmu tersebut. Melalui pendekatan estetika akan digali aspek formalistik tiap logo brand UMKM produk olahan Depok dan konsistensinya. Makna dibalik aspek formal logonya dianalisis dikaitkan dengan ilmu pemasaran dimana visual branding idealnya dapat membedakan suatu produk dengan yang lainnya agar dapat bertahan dan memiliki nilai tambah. Selain itu, identitas brand melalui visual branding logonya juga dikaji terkait produk asal suatu daerah.

Teknik pengumpulan data pada penelitian ini diantaranya melalui observasi, wawancara dan literatur. Kegiatan observasi non-partisifatif pada sentra UMKM Depok di ITC Depok, sentra oleh-oleh Depok Pesona Rasa, serta toko dari satu brand untuk mengamati keberadaan kelima brand produk olahan 
belimbing UMKM Depok berkaitan dengan visual branding. Wawancara dilakukan pada pihak UMKM serta pakar branding. Pihak UMKM diwawancarai secara mendalam guna mendapatkan data mengenai produknya, logonya dan desain kemasan serta media promosi. Pakar branding diwawancarai untuk mendapat informasi mengenai pandangannya terhadap visual branding UMKM. Penelitian ini juga menggunakan teknik triangulasi teknik pengumpulan data.

\section{HASIL DAN DISKUSI}

\section{Keberadaan Produk UMKM Depok}

Depok merupakan kota dengan banyak UMKM baik jumlah maupun jenis. Kondisi branding dalam hal identitas visualnya beragam dan belum merata, dimulai dari yang tidak mempunyai brand sampai yang memiliki branding yang baik. Produk belimbing olahan Depok mengarah kepada posisinya secara umum bukan "produk khas Depok", "makanan khas Depok" maupun "produk unggulan/ OVOP (One Product One Village) Depok" melainkan sebagai produk lokal asal Depok karena untuk dapat menjadi produk khas maupun produk daerah harus memenuhi persyaratan tertentu. Oleh sebab itu, maka selanjutnya penyebutan secara umum bagi produk belimbing olahan Depok ialah produk lokal asal Depok.

\section{Identitas visual berkaitan dengan Depok}

Dalam konsep Regional branding, identitas daerah menjadi penting untuk diangkat agar produk memiliki nilai tambah dan keunikan tersendiri. Oleh sebab itu, perlu dilakukan identifikasi ikon, simbol, yang berkaitan dengan Kota Depok. Sejarah dan tradisi di Depok dapat dilihat pada logonya dimana berisi lambang, warna dan tulisan yang memiliki warna tertentu. Gambar 1 berikut ini merupakan logo kota Depok: 


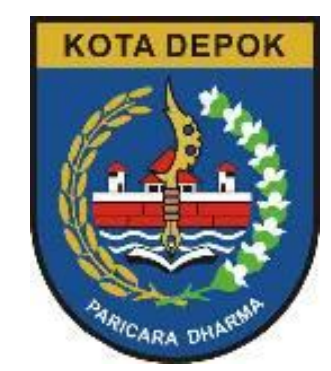

Gambar 1 Logo Kota Depok

Sumber: $\underline{\text { www.depok.go.id }}$

Diantara bentuk yang ada di logo kota Depok, nampaknya salah satu artefak yang menjadi ciri khas Depok sebagai bagian dari Jawa Barat ialah Kujang. Padi dan kapas, pendopo, gelombang air, perisai, gedung, batu bata, mata pena, buku, adalah objek yang umum ditemukan sebagai simbol dari suatu logo. Warna pada logonya memiliki makna simbolis diantaranya kuning emas (melambangkan kemuliaan), merah bata (melambangkan keberanian), putih (melambangkan kesucian), hijau (melambangkan harapan masa depan serta menunjukkan Daerah yang subur), hitam (melambangkan keteguhan), dan biru (melambangkan keluasan wawasan dan kejernihan pikiran).

Selain logo Kota Depok, melalui hasil pengamatan ditemui gapura di daerah Sawangan, Depok dimana disebelah kanan dan kirinya terdapat patung belimbing berukuran besar yang nampaknya dijadikan salah satu penanda/ landmark kota Depok karena ikon kota Depok adalah belimbing (Gambar 2).

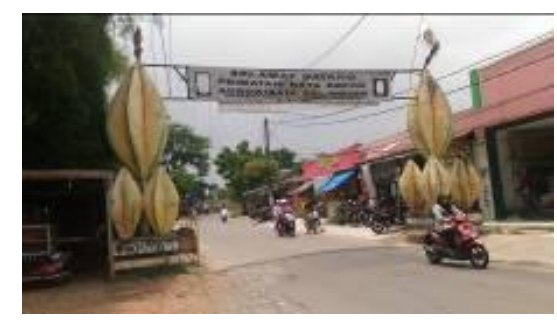

Gambar 2 Gapura dengan ikon belimbing Sumber: Listya dan Rukiah, 2017

Belimbing Dewa sebagai belimbing unggulan Kota Depok perbedaannya dengan belimbing bukan jenis dewa terletak pada ukurannya, rasanya, dan kandungan airnya. Jika belimbing dewa secara visual dibedakan dengan belimbing 
biasa tidak nampak perbedaan yang berarti oleh karena itu belimbing dewa nampaknya tidak dapat menjadi ciri visual Kota Depok dalam penggunaannya sebagai ilustrasi atau foto. Ilustrasi atau foto belimbing dewa dapat dikenali sebagai belimbing biasa jika keberadaannya tidak disandingkan dengan belimbing bukan jenis dewa. Perlu adanya perlakuan khusus seperti penambahan elemen ataupun penambahan tagline misalnya agar gambar belimbing Dewa lebih kuat sebagai ciri khas Depok dalam desain logo.

Depok juga memiliki batik yang motifnya khas. Motifnya berupa simbolsimbol yang maknanya berkaitan dengan filosofi tertentu. Simbol Paricara Dharma, semboyan Kota Depok yang menjadi amanah semua komponen masyarakat Depok, yang mengutamakan pengabdian yang baik, benar dan adil. Simbol Sayap diartikan sebagai mengayomi serta mengangkat tinggi harkat, martabat dan derajat masyarakat Depok. Simbol Buah Belimbing dan Ikan Memphis melambangkan keunggulan Kota Depok. Simbol Mega Mendung bermakna tingginya cita-cita dan semangat yang sejuk. Jembatan Panus, Margonda, Gedung Tua dan Gong Sibolong, serta Topeng Cisalak menunjukkan masyarakat Depok tidak akan pernah meninggalkan dan akan selalu menghormati sejarah dan budaya para pendahulunya. Warna dasar batiknya yaitu kuning keemasan, maroon, jingga, biru, biru tua dan cream, yang melambangkan kewibawaan, keteduhan, ketenangan dan keberanian.
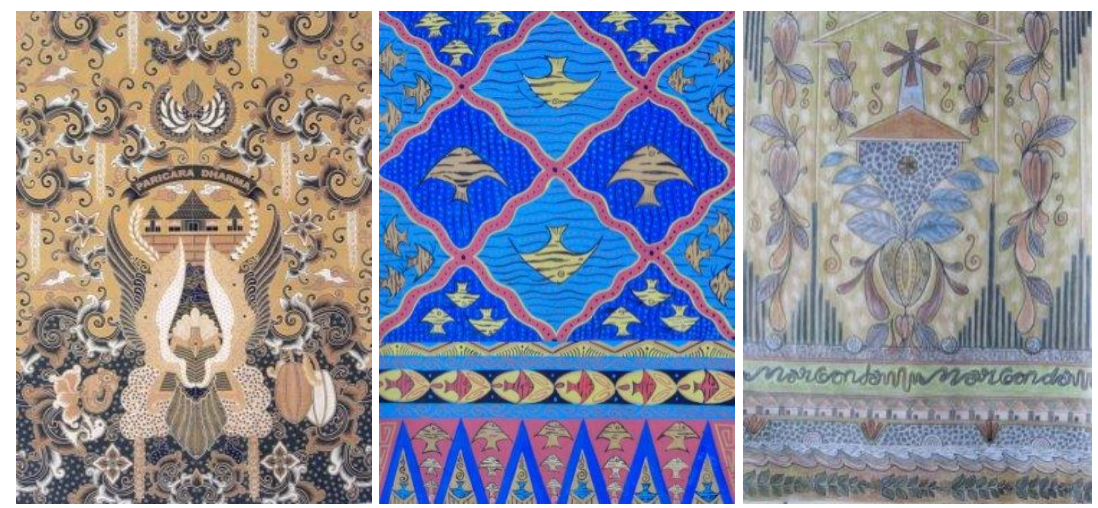

Gambar 3 Motif batik Depok

Sumber: www.depokita.com 
Berdasarkan data yang diperoleh, dapat diidentifikasi secara visual, identitas khas Kota Depok ialah pertama, Belimbing yang sudah jelas menjadi ikon kota Depok sampai saat ini. Kedua, simbol-simbol dan artefak seni budaya berupa Paricara Dharma, Simbol Sayap, simbol Ikan Memphis, motif Mega Mendung, Jembatan Panus, Margonda, Gedung Tua dan Gong Sibolong, Topeng Cisalak, Kujang. Kemudian terakhir, warna-warna khas kota Depok yang ditemukan pada logo Kota Depok diantaranya kuning emas, merah bata, putih, hijau, hitam, dan biru. Selain warna pada lambang kotanya, Depok juga memiliki ciri khas warna batik yaitu kuning keemasan, maroon, jingga, biru, biru tua dan cream. Hasil identifikasi ini akan dihubungkan dengan hasil identifikasi desain logo kelima brand yang diteliti untuk menemukan apakah desain logo mengangkat identitas yang berkaitan dengan Depok atau tidak.

\section{Logo kelima brand produk belimbing olahan UMKM Depok}

Setiap merek produk belimbing olahan Depok telah memiliki logo, dapat dilihat pada tabel 1 dibawah ini:

Tabel 1 Daftar logo kelima merek produk belimbing olahan UMKM Depok

\begin{tabular}{|c|c|c|c|}
\hline No. & merek & logo & Versi Logo \\
\hline \multirow[t]{4}{*}{1} & Rasa Dewa & & $\begin{array}{l}\text { "logo versi belimbing } \\
\text { kuning" }\end{array}$ \\
\hline & & & $\begin{array}{l}\text { "logo Rasa Dewa versi } \\
\text { belimbing kuning - } \\
\text { kuning terang" }\end{array}$ \\
\hline & & & $\begin{array}{l}\text { "logo Rasa Dewa versi } \\
\text { logotype merah" }\end{array}$ \\
\hline & & & $\begin{array}{l}\text { "logo Rasa Dewa versi } \\
\text { logotype kuning" }\end{array}$ \\
\hline
\end{tabular}




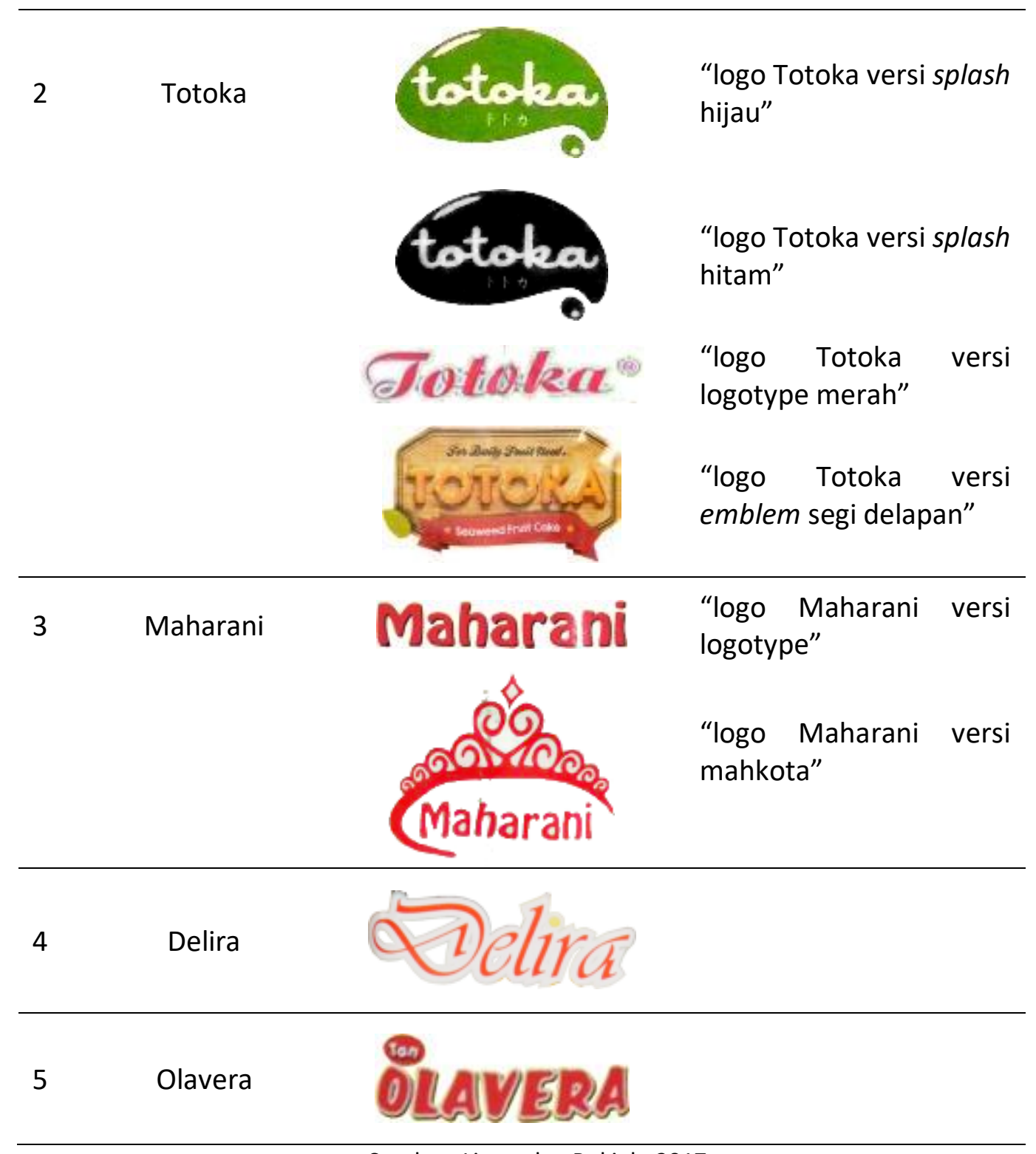

Sumber: Listya dan Rukiah, 2017

Untuk mempermudah analisis logo, maka pada tabel 1 diatas, semua logo merek Rasa Dewa, Totoka, dan Maharani diberi nama sesuai versinya karena beberapa brand memiliki logo yang berbeda-beda dalam desain kemasan di berbagai produknya maupun media promosi. 


\section{Estetika desain Logo Rasa Dewa}

Logo Rasa Dewa ada empat versi yang nampaknya masih konsisten terimplementasi pada kemasan dan media promosinya meski kehadiran logonya tidak selalu memuat gambar belimbing. Selain itu, terkadang effect pada logonya berbeda. Logo Rasa Dewa yang bertipe name and symbol (gabungan antara gambar dan teks) yaitu logo Rasa Dewa versi belimbing kuning dan logo Rasa Dewa belimbing kuning-kuning terang. Logo ini mengandung gambar figuratif berupa gambar potongan melintang belimbing, warna kuning dan merah, bentuk huruf kapital tipe serif yang termodifikasi. Potongan belimbing secara ikonografi dapat dimaknai sebagai usaha mengasosiasikan dengan bahan dasar produknya yaitu buah belimbing. Potongan melintang buah belimbing tersebut secara visual menyerupai bintang yang dapat dimaknai sebagai objek yang berada di langit (sesuatu yang tinggi).

Secara umum penggunaan gambar bintang dapat merepresentasikan kualitas yang tinggi. Bintang menyatakan tingkat kualitas contohnya pada rating maupun label bintang pada hotel. Hal tersebut diafirmasi oleh Lejar Tri Ayunita pemilik UMKM Rasa Dewa dimana bintang dimaksudkan sebagai juara, diharapkan brand Rasa Dewa menjadi juara diantara produk sejenis. Meski begitu, secara raut bentuk, gambar belimbing yang juga bintang nampaknya masih kurang unik berdasarkan hasil observasi pada logo di internet yang juga mengandung elemen visual bintang.

Warna merah merupakan gelombang elektromagnetik terpanjang sehingga dapat dengan cepat ditangkap oleh mata. Warna menghasilkan kesan tertentu dan memiliki makna baik positif maupun negatif. Studi terhadap warna cukup banyak termasuk dalam bidang desain, dan pemasaran. Warna membawa makna intrinsik yang menjadi pusat identitas brand, berkontribusi terhadap pengenalan brand (Abril, dkk, 2009). Penelitian Mehta dan Zhu (2009: 1046) menunjukkan bahwa merah mengarah pada kinerja yang lebih baik pada tugas yang berorientasi pada detail. Merah melambangkan kegembiraan (Labrecque \& Milne, 2012: 714). 
Warna merah langsung ditangkap oleh mata dengan cepat menarik perhatian. Warna merah pada logo Rasa Dewa sepertinya dikaitkan pada suatu penonjolan, yang utama. Hal tersebut berelasi dengan ikon potongan belimbing melintang yang juga bintang dimana bermakna yang teratas. Warna kuning diasosiasikan pada warna alamiah buah belimbing seperti yang dikatakan Lejar bahwa logo Rasa Dewa dimaksudkan agar terbaca sebagai "rasa belimbing dewa".

Huruf pada logotype Rasa Dewa merupakan tipe serif/ berkait yang dimodifikasi bagian kakinya. Secara pra-ikonografi, Pada logonya terdapat pendistorsian serif huruf $R$ serta pendistorsian kaki huruf $R$ dan $A$. pendistorsian tersebut dapat dimaknai sebagai usaha untuk menampilkan keunikan visual dengan memodifikasi huruf dibandingkan hanya menampilkan huruf tersebut apa adanya. Jenis huruf serif dengan kaki yang mengotak berkesan official dan typeface yang berat berkesan kuat, agresif dan maskulin (Arker, 1997; White, 1988; Baylis, 1955 dalam Brumberger, 2003: 206). Format huruf pada logotype Rasa Dewa adalah kapital yang merepresentasikan ketegasan dan berani. Jika dikaitkan dengan makna gambar figuratif dan warnanya dapat ditarik kesimpulan bahwa Rasa Dewa bermakna produk yang paling menonjol, yang paling utama.

\section{Estetika desain Logo Totoka}

Logo Totoka ada empat versi dengan tiga variasi bentuk sekaligus warna yang sangat berbeda diantaranya logo Totoka versi splash hijau, logo Totoka versi splash hitam, logo Totoka versi logotype merah, logo Totoka versi emblem segi delapan. Bentuk formal pada logo Totoka berupa warna merah, hijau, hitam, kuning dan keluarga kuning, gambar abstrak maupun figuratif, bentuk huruf handwritten (seperti tulisan tangan) dan dekoratif dengan variasi format huruf besar/ kapital maupun huruf kecil. Gambar splash bentuk abstrak mengasosiasikan percikan. Percikan nampaknya dihubungkan dengan produknya yang berwujud cair karena logo ini ada pada kemasan produk sirup dan jus. Gambar percikan itu juga dapat 
dilihat sebagai bubble chat. Bubble chat dapat diartikan sebagai suasana mengobrol santai melihat bentuknya yang fleksibel dinamis.

Kategori Huruf logotype pada keempat logo Totoka dapat terbagi dua yaitu tipe handwritten (versi splash hijau, versi splash hitam, versi logotype merah) dan tipe dekoratif membulat diujung (versi emblem segi delapan). Mackiewicz dalam Shaikh (2007) menentukan huruf yang berkesan "friendly" ialah yang memiliki terminal yang rounded (membulat, tidak kaku) seperti pada logotype Totoka versi splash dan versi emblem segi delapan sedangkan logo Totoka versi logotype merah termasuk dalam kategori script yang secara umum diketahui menggambarkan personal dan elegan. Jika makna huruf yang friendly ini dikaitkan dengan gambarnya yang juga bersifat fleksibel maka logotype Totoka dapat dimaknai sebagai bersahabat, dinamis dan fleksibel.

Tampilan visual logonya jika dikaitkan dengan desain label kemasannya yang juga berkesan dinamis cukup menguatkan kesan yang ingin ditampilkan. Satu hal yang menjadikan Totoka ini menjadi perhatian peneliti adalah karena pada logo versi splash terdapat huruf Jepang. Dikaitkan dengan namanya nampaknya huruf Jepang ada kaitannya dengan nama Totoka yang terdengar seperti bahasa Jepang. Berdasarkan seorang informan karyawan pemilik UMKM tersebut disebutkan bahwa pemilik Totoka memiliki anak yang berkuliah di Jepang. Berdasarkan hal tersebut dapat disimpulkan bahwa merek Totoka mendapat pengaruh budaya Jepang akibat pengalaman pemilik brand-nya.

Secara keseluruhan warna logo Totoka ada beberapa yakni versi hijau, versi hitam, versi kuning jingga, dan versi merah. Warna merah masih berdekatan dengan jingga dan kuning yang ketiganya sama-sama warna hangat yang mengekspresikan kegembiraan dan kehangatan. hijau dimaknai sebagai warna alam (Kaya dan Epps dalam Labrecque dan Milne, 2012: 714) yang jika dimaknai pada logo Totoka ialah sebagai produk berbahan dasar buah belimbing yang berasal dari alam maupun ingin merepresentasikan kealamian produknya. Logo versi splash hitam sepertinya 
bersifat teknis karena pada label kemasan sirup belimbing memang keseluruhan elemen kemasannya berwarna hitam.

\section{Estetika desain Logo Maharani}

Logo Maharani ada dua versi yaitu versi logotype dan versi mahkota (versi lengkap). Bentuk formalnya yakni berupa gambar figuratif mahkota, warna merah, dan huruf bertipe San serif. Makna yang terungkap yaitu gambar mahkota erat kaitannya dengan kerajaan, raja dan ratu yang diasosiasikan sebagai kekuasaan. Menurut Rustiana pemilik UMKM Ana Kreatif yang memproduksi produk belimbing olahan merek Maharani, nama Maharani berasal dari nama anak perempuannya. Rustiana mengatakan bahwa mahkota tidak ada maksud tertentu pada logonya, melainkan hanya untuk menampilkan sesuatu yang berbeda. Pernyataan Rustiana mengenai nama anak perempuannya nampaknya jika dihubungkan dengan adanya gambar mahkota ratu pada logonya adalah sebagai bentuk ekspresi rasa kasih sayang terhadap anak perempuannya yang dianggapnya sebagai seorang putri. Jika dikaitkan dengan keunikan brand dapat dimaknai sebagai usaha untuk menampilkan sesuatu yang spesial. Gambar figuratif mahkota ini juga menerapkan prinsip penekanan.

Kata spesial juga tepat untuk melambangkan produk dodol Maharani yang spesial karena menurut Rustiana, produk dodol belimbingnya menggunakan komposisi belimbing yang lebih banyak dibanding dodol belimbing lainnya, juga Maharani menggunakan kuali untuk memasak dodol sehingga aroma dan rasanya lebih lezat.

Warna logo Maharani adalah merah. Gambar figuratif mahkota yang merah terlihat berprinsip kesatuan dengan merahnya logotype. Huruf pada logotype Maharani berjenis sans serif. San serif secara tipikal dipersepsikan sebagai yang lebih "bersih" dan lebih modern daripada serif (Benson 1985; Kostelnick \& Roberts 1998 dalam Brumberger, 2003: 206). 


\section{Estetika desain Logo Delira}

Bentuk formal dalam logonya berupa huruf tanpa adanya gambar figuratif maupun abstrak serta warnanya yang merah. Emphasis pada logonya terletak pada titik sebagai elemen huruf i namun karena warnanya kuning kurang terlihat jelas. Warna logo Delira sama dengan merek lainnya yang sudah dibahas sebelumnya dimana secara fisik warna merah paling cepat ditangkap oleh mata dan secara makna merah menggambarkan kegembiraan. Jenis huruf pada logotype Delira ialah handwritten/script yang mengesankan personal, dan elegan.

\section{Estetika desain Logo Olavera}

Sama seperti Delira, bentuk formal dalam logonya berupa huruf tanpa adanya gambar figuratif maupun abstrak dan warna merah. Emphasis pada logonya terletak pada lingkaran merah berukuran kecil diatas nama brand-nya. Makna yang didapat ialah kegembiraan pada makna warna merah. Jenis huruf pada logotype Delira bertipe san serif yang mengesankan bersih dan lebih modern yang kesan tersebut secara keseluruhan juga nampak pada labelnya.

\section{Keunikan brand dan identitas brand Produk belimbing olahan UMKM Depok}

Dari hasil analisis bentuk formal kelima logo dapat disimpulkan bahwa visual branding kelima brand produk belimbing olahan produksi UMKM Depok beberapa diantaranya berusaha untuk tampil berbeda dalam hal bentuk namun belum memperlihatkan keunikan yang ditinjau dari esensi branding yang membedakan suatu produk dengan produk lainnya dalam hal warna karena kelimanya mempunyai logo yang mengandung warna merah.

Dalam hal gambar (ikon figuratif maupun abstrak) diperoleh hasil analisis logo Rasa Dewa menekankan produk berbahan buah belimbing sekaligus gambar tersebut dapat dilihat sebagai bintang yang mencitrakan produk yang unggul (juara); Totoka mencitrakan friendly dan kedinamisan yang biasanya terkait usia muda maupun yang berjiwa muda serta mencitrakan kealamian produk; dan 
Maharani merepresentasikan sesuatu yang spesial. Delira dan Olavera logonya bertipe logotype yang nampaknya bentuk hurufnya tidak dimodifikasi dari huruf yang telah tersedia dan berwarna sama dengan semua brand yang ada sehingga kurang unik.

Eka Sofyan, seorang pakar Branding mengatakan suatu produk dapat teridentifikasi sebagai brand, jika berbeda dari produk lainnya. Eka Sofyan berpendapat bahwa untuk merepresentasikan suatu produk tidak harus menampilkan secara langsung produk tersebut menjadi gambar figuratif, jika dikaitkan dengan produk belimbing olahan Depok ini, tidak harus menampilkan belimbing jika produknya berbahan buah belimbing. Berkaitan dengan itu, Eka Sofyan berpendapat bahwa untuk logo produk makanan dan minuman akan lebih baik jika bertipe logotype akan lebih dibanding logo yang mengandung gambar figuratif yang secara langsung dihubungkan dengan produknya.

Mengenai branding untuk produk lokal yang juga berpotensi produk unggulan daerah, Eka Sofyan menuturkan pemikirannya bahwa merek lokal tersebut sebaiknya tampil kelokalannya melalui visual branding-nya. Tampil kelokalannya tidak terbatas hanya menggunakan ikon-ikon yang identik pada daerah tersebut (misalnya bangunan, ragam hias, logo daerah, artefak budaya), melainkan kelokalan seperti cara memasak, gotongroyong ibu-ibu setempat dalam membuat produk itu, petani setempat, dapat diangkat menjadi identitas suatu daerah dalam visual branding.

Sebaiknya, merek daerah tertentu tidak nampak seperti produk dari daerah lain. Untuk itu, produk belimbing olahan yang merupakan produk unggulan Depok sebaiknya tampil "Depok". Kekhasan Depok tidak harus direpresentasikan dengan identitas kota Depok ataupun landmark Depok. Rekomendasi desain logo untuk setiap brand Tampil "Depok" dalam studi ini ialah misalkan desain logotype dibuat customized sesuai dengan karakter yang berkaitan dengan Depok. Logogram dibuat bentuk figuratif yang dapat memanfaatkan keunggulan atau keunikan tiap produknya. Brand Maharani misalnya yang masih menggunakan 
kuali untuk memasak dodolnya bisa diangkat sebagai keyvisual logo. Brand Rasa Dewa yang logonya menonjolkan belimbingnya dapat lebih dibuat khas bentuk belimbing dewa-nya maupun diperkuat dengan tagline.

Warna logo idealnya berbeda dengan yang lainnya. Perlu dilakukan riset pesaing bagi produk baru guna menciptakan identitas visual yang khas dan berbeda dengan yang lainnya. Jika warnanya sama, dapat membuat keberbedaan dari elemen yang lainnya. Bagi semua brand, konsistensi sangat penting diterapkan agar membentuk impresi sehingga diingat oleh khalayak.

\section{KESIMPULAN}

Penelitian ini menunjukkan adanya perbedaan maupun kesamaan diantara kelima brand tersebut. Kesamaan dalam logo kelima brand adalah pada unsur warna, yang dalam visual branding hal ini tidak mencerminkan keunikan padahal warna adalah hal yang sangat penting. Dari aspek gambar dan huruf, tiga dari lima brand memiliki keberbedaan satu dengan yang lainnya, namun belum memperlihatkan identitas yang berkaitan dengan keunikan brand-nya, termasuk salah satu brand ditemukan terdapat adanya tulisan jepang. Dua brand lainnya terlihat mirip satu sama lainnya sehingga direkomendasikan untuk dievaluasi kembali visual branding-nya.

Aspek formalistik desain logo pada visual branding yang terdiri dari bentuk figuratif maupun abstrak, bentuk huruf dan warna idealnya dibuat berbeda dengan pesaingnya dan dihubungkan dengan brand. Beberapa UMKM dengan produk unggulan Depok ini mendesain logonya sendiri dimana dasar pemilihan unsur desainnya belum mempertimbangkan pembentukan identitas yang berhubungan dengan brand-nya, juga keberbedaannya secara visual dengan pesaingnya sehingga daya saingnya cenderung lemah baik dikalangan sesama UMKM maupun non UMKM. Oleh karena itu, perancangan logo membutuhkan pengetahuan dan pengalaman pemilik UMKM dan perancang logonya. dibutuhkan riset termasuk desain logo pesaing sebelum mendesain identitas visual. Keunikan 
tiap brand harus muncul meskipun dalam studi kasus ini kelima brand sama-sama UMKM yang menjual produk olahan dari komoditas unggulan Depok, yang kelimanya berpotensi untuk berkembang, terlebih UMKM saat ini sangat didukung oleh pemerintah dan instansi lainnya.

Identitas visual yang ada pada Depok teridentifikasi berupa ikon, simbol dan warna yang ada pada lambang kotanya dan juga artefak seni budayanya. Dengan melihat identitas Depok tersebut dikaitkan dengan tampilan logo, maka ditemukan bahwa logo sebagai bagian dari visual branding dari kelima brand belum merepresentasikan identitasnya sebagai produk lokal asal Depok.

\section{PERNYATAAN PENGHARGAAN}

Apresiasi dan terima kasih kepada Direktorat Riset dan Pengabdian Masyarakat, Dirjen Penguatan Riset dan Pengembangan, Kementerian Riset, Teknologi dan Pendidikan Tinggi yang telah membiayai kegiatan penelitian Dosen Pemula (PDP) Tahun 2017 dengan judul: "Kajian Visual Branding Produk Olahan belimbing UMKM Depok".

Terima kasih juga kepada Lembaga Penelitian dan Pengabdian Masyarakat Universitas Indraprasta PGRI yang telah membantu kegiatan penelitian ini melalui Kontrak Penelitian No. 0568/SKP.LT/LPPM/UNINDRA/VI/2017, tanggal 5 Juni 2017.

\section{DAFTAR PUSTAKA}

Abril, P. S., Olazabal, A. M., \& Cava, A., 2009. Marketing and the law. Journal of the Academy of Marketing Science, 37(3), 375-377.

Ahonen, M., 2008. Branding-does it even exist among SMEs. In Proceedings of the $16^{\text {th }}$ Nordic Conference on Small Business Research (Vol. 202).

Brumberger, E., 2003. The rhetoric of typography: The persona of typeface and text, Technical Communication, 50 (2), 206-223. 
Davidson, J., 2009. Icon, iconography, iconology: Visual branding, banking and the case of the bowler hat. Accounting, Auditing \& Accountability Journal, 22(6), 883-906.

Durrieu, F., 2008. Impact of brand identity on labelling: the case of regional branding. $4^{\text {th }}$ International Conference of the Academy of Wine Bussiness Research, Siena, 17-19 July 2008.

Farhana, M., 2012. Brand elements lead to brand equity: differentiate or die. Information Management and Business Review, 4(4), 223-233.

Haiqal, M. K. \& Hidayat, S., 2017. Penerapan identitas visual pada media promosi website wisata kerajinan raja polah. Demadia. 2(2), 182-199.

Hardy, G., 2011. Smashing logo design: The art of creating visual identities. Chichester, John Willey and Sons Ltd.

Kirk, L., 2013. Visual branding in graphic design. (honors theses). University of Southern Missisippi.

Kotler, Philip, 2000. Marketing management, 10th ed., Prentice-Hall, Sydney.

Labrecque, L. I., \& Milne, G. R., 2012. Exciting red and competent blue: the importance of color in marketing. Journal of the Academy of Marketing Science, 40(5), 711-727.

Mehta, R. P. and Zhu, R. J., 2009. Blue or Red? exploring the effect of color on cognitive performance, in NA - Advances in Consumer Research Volume 36, eds. Ann L. McGill and Sharon Shavitt, Duluth, MN: Association for Consumer Research, Pages: 1045-1046.

Septiningtyas, A. \& Soewardikoen, D. W., 2018. Perancangan identitas visual dan promosi sasirangan banjarbaru. Demandia. 3(1), 1-18.

Shaikh, A. D., 2007. Psychology of onscreen type: Investigations regarding typeface personality, appropriateness, and impact on document perception (Doctoral dissertation). 
Sudarwati, Y., \& Satya, V., 2013. Strategi pengembangan merek usaha mikro,kecil, dan Menengah (microfinance, small, and medium enterprises brand ing strategy). Jurnal Ekonomi \& Kebijakan Publik, 4 (1), 89-101.

Van den Bosch, A. L., De Jong, M. D., \& Elving, W. J., 2006. Managing corporate visual identity: Exploring the differences between manufacturing and service, and profit-making and nonprofit organizations. The Journal of Business Communication (1973), 43(2), 138-157.

Walker, J. A., 2010. Desain, sejarah, budaya: Sebuah pengantar komprehensif. Yogyakarta: Jalasutra.

Wheeler, A., 2011. Designing brand identity, an essential guide for the entire branding team. (3rd ed.). Canada: Wiley. 